\title{
Repercussões fetais e possíveis complicações da COVID-19 durante a gestação
}

Fetal repercussions and possible complications of COVID-19 during pregnancy

Repercusiones fetales y posibles complicaciones de COVID-19 durante el embarazo

\begin{abstract}
RESUMO
Objetivou-se identificar as repercussões e possíveis complicações da COVID-19 durante a gestação. Trata-se de uma revisão integrativa da literatura realizadas nas bases de dados LILACS, Organização Mundial da Saúde (OMS), Ministério da Saúde e FEBRASGO. Ao final, foram selecionados 11 estudos que foram analisados de forma qualitativa de acordo com a temática abordada e seus resultados. Nota-se que por ser uma patologia altamente contagiosa, os cuidados com essa mãe e esse feto devem ser mais cautelosos, para evitar complicações, que por se tratar de uma gestante, estão mais suscetíveis.
\end{abstract}

DESCRITORES: Coronavírus; Gestação; Pesquisa Fetal; Pré-Natal.

\section{ABSTRACT}

The aim was to identify the repercussions and possible complications of COVID-19 during pregnancy. This is an integrative literature review carried out in the LILACS, World Health Organization (WHO), Ministry of Health and FEBRASGO databases. At the end, 11 studies were selected and analyzed qualitatively according to the theme addressed and its results. It should be noted that because it is a highly contagious pathology, care for this mother and fetus should be more cautious, to avoid complications, which, as a pregnant woman, are more susceptible.

DESCRIPTORS: Coronavirus; Gestation; Fetal Research; Prenatal

\section{RESUMEN}

El objetivo fue identificar las repercusiones y posibles complicaciones de COVID-19 durante el embarazo. Esta es una revisión integral de la literatura realizada en las bases de datos de LILACS, la Organización Mundial de la Salud (OMS), el Ministerio de Salud y FEBRASGO. Al final, se seleccionaron 11 estudios y se analizaron cualitativamente de acuerdo con el tema abordado y sus resultados. Cabe señalar que debido a que es una patología altamente contagiosa, el cuidado de esta madre y el feto debe ser más cauteloso, para evitar complicaciones que, como mujer embarazada, son más susceptibles.

DESCRIPTORES: Coronavirus; Gestación; Investigación fetal; Prenatal

RECEBIDO EM: 22/05/2020 APROVADO EM: 23/05/2020

\section{Nathalia Cristina Machado Prado Ramiro}

Acadêmica do Curso de Graduação em Enfermagem do Centro Universitário São Camilo. SP/Brasil. https://orcid.org/00000002-6949-6134

\section{Mariana de Souza Pereira}

Acadêmica do Curso de Graduação em Enfermagem do Centro Universitário São Camilo. SP/Brasil. https://orcid.org/00000002-8384-8538

\section{Rafaela Silva de Souza}

Acadêmica do Curso de Graduação em Enfermagem do Centro Universitário São Camilo. SP/Brasil. https://orcid.org/00000001-8776-9506

\section{Luciane Andrea Aver}

Enfermeira. Mestre Ciências da Saúde. Especialista em Enfermagem Obstétrica, Enfermagem do Trabalho e Administração Hospitalar. Docente do Centro Universitário São Camilo. SP/Brasil. https://orcid.org/0000-0002-2432-7628 


\section{INTRODUÇÃO}

E m dezembro de 2019, foram registrados os primeiros casos de pacientes com sintomas respiratórios graves que foram acometidos pelo novo vírus denominado Novo Coronavírus, patologia COVID-19 $9^{(1)}$. Desde então, houve uma rápida disseminação do vírus pelo mundo e, em 11 de março de 2020, a Organização Mundial da Saúde (OMS) declarou uma situação de pandemia.

Os sintomas da COVID-19 são variados e, dessa forma, o paciente que tenha contraído o novo vírus pode apresentar um quadro assintomático como pode ter sintomas mais graves, necessitando de intervenções hospitalares ${ }^{(2)}$.

No Brasil, o primeiro caso foi registrado na cidade de São Paulo no dia 26 de fevereiro de 2020, em um paciente do sexo masculino, de 61 anos de idade e que esteve na Itália. Este paciente foi tratado em domicílio e nos dias atuais está totalmente curado ${ }^{(1)}$. Os números de COVID-19 no Brasil vêm aumentando cada vez mais e, atualmente, foram confirmados 241.080 casos, 16.118 óbitos e 94.122 pacientes recuperados ${ }^{(2)}$.

Com a rápida disseminação do vírus, as sociedades científicas nacionais e internacionais e o Ministério da Saúde do Brasil têm publicados manuais e materiais informativos, com o intuito de orientar a população e os profissionais da saúde sobre medidas que possam diminuir o contágio e minimizar os efeitos da contaminação.

Em relação à gestação, não há evidências que a COVID-19 possa apresentar consequências graves à gestante, comparada com outras infecções respiratórias com etiologia viral. As gestantes com a COVID-19 apresentam um quadro clínico semelhante ao de adultos que não estão gestantes, com os sintomas mais comuns apresentados são a febre alta e a tosse $\mathrm{e}^{(2)}$.

As gestaçôes de baixo risco possuem a mesma probabilidade de apresen-
Em relação à

gestação, não há

evidências que

a COVID-19

possa apresentar

consequências

graves à gestante,

comparada com

outras infecções

respiratórias com

etiologia viral.

As gestantes com

a COVID-19

apresentam um

quadro clínico

semelhante ao de

adultos que não

estão gestantes, com

os sintomas mais

comuns apresentados

são a febre alta e a

$\operatorname{tosse}^{(2)}$. tarem as mesmas complicações que a população em geral. Porém, gestantes que possuem doenças de base, como hipertensão, diabetes ou doenças crônicas respiratórias - asma e doença pulmonar obstrutiva crônica (DPOC) - apresentam uma taxa de complicações mais elevada. Gestantes que apresentarem idade gestacional acima de 28 semanas devem estar atentas em relação ao isolamento social e às medidas de prevenção à patologia, pois podem apresentar um risco maior à prematuridade ${ }^{(3)}$.

Atualmente, após testes realizados em amostra de placentas, sangue do cordão umbilical, muco vaginal e líquido amniótico, não há evidencias que a COVID-19 possa ser transmitida de mãe para filho ${ }^{(4)}$.

Desta forma, objetivou-se identificar as repercussões e possíveis complicações da COVID-19 durante a gestação.

\section{METODOLOGIA}

Trata-se de uma revisão integrativa da literatura, realizada nas bases de dados eletrônicas LILACS, Organização Mundial da Saúde (OMS), Ministério da Saúde e FEBRASGO, com o intuito de responder à questão norteadora: Quais repercussões e possíveis complicações da COVID-19 durante a gestação?

A busca e seleção foram realizadas no período de 15 a 18 de maio de 2020 . Ao utilizar os Descritores em Ciências da Saúde (DeCS): "Coronavírus", "Gestação" e "Pesquisa Fetal”; foram encontrados 412 estudos. Logo após, foram incluídos os critérios de elegibilidade. Para inclusão do estudo, atendeu às seguintes exigências: estudos em formatos de artigo científico; publicados de forma on-line, gratuita e em texto completo; publicados no ano de 2020; no idioma português; e que abordassem a temática aqui discutida. Como critério de exclusão, os estudos publicados em duplicata nas bases citadas. 
Figura 1. Fluxograma de identificação, triagem, elegibilidade e inclusão de referências. São Paulo, SP, Brasil, 2020

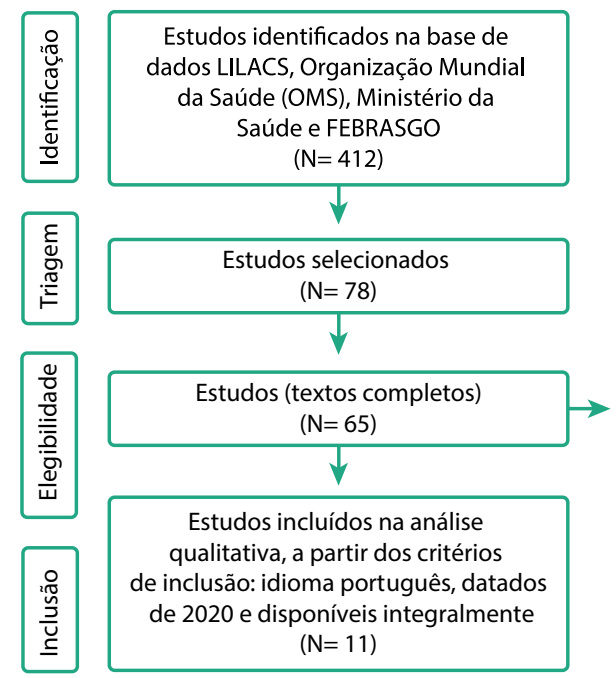

Estudos excluídos por se repetirem ou não apresentarem relação com a temática $(\mathrm{N}=54)$
Ao final, foram selecionados 11 estudos, como verifica-se no fluxograma abaixo (Figura 1).

\section{RESULTADOS E DISCUSSÃO}

Observa-se na Figura 2, o quadro sinóptico dos artigos selecionados para a presente revisão integrativa com as suas respectivas variáveis: ano de publicação, autores, título e objetivo(s).

$\mathrm{Na}$ Figura 3, verifica-se o quadro sinóptico dos artigos selecionados com seus respectivos títulos e resultados.

A nova infecção pelo coronavírus (SARS-CoV-2), chamada de COVID-19, acomete a população geral, inclusive gestantes, porém como qualquer outra patologia, por conta das alterações gestacionais presentes no organismo da mulher devido à gestação, a COVID-19 pode se manifestar de maneira diferente na gestante.

\section{Figura 2. Quadro sinóptico dos artigos selecionados contendo ano de publicação, autor e objetivos. São Paulo, SP, Brasil, 2020}

\begin{tabular}{|c|c|c|c|c|}
\hline NUMERAÇÃO & $\begin{array}{c}\text { ANO DE } \\
\text { PUBLICAÇÃO }\end{array}$ & AUTORES & TÍTULO & OBJETIVO (S) \\
\hline $1^{\circ}$ & Março/2020 & Osanan, Gabriel Costa & $\begin{array}{l}\text { Coronavirus na gravidez: } \\
\text { considerações e recomen- } \\
\text { dações sogimig }\end{array}$ & $\begin{array}{l}\text { Auxiliar os profissionais da saúde na con- } \\
\text { dução das gestantes durante o período } \\
\text { dessa epidemia. }\end{array}$ \\
\hline $2^{\circ}$ & Abril/2020 & $\begin{array}{l}\text { ESTRELA, Fernanda Ma- } \\
\text { theus }\end{array}$ & $\begin{array}{l}\text { Gestantes no contexto da } \\
\text { pandemia da Covid-19: refle- } \\
\text { xões e desafios }\end{array}$ & $\begin{array}{l}\text { Refletir sobre o estar da gestante em tem- } \\
\text { pos de pandemia da Covid-19 e a impor- } \\
\text { tância do cuidado profissional, sobretudo } \\
\text { de enfermeiras, a fim de superar os inúme- } \\
\text { ros desafios que permeiam esse desafio. }\end{array}$ \\
\hline $3^{\circ}$ & Março/2020 & DASHRAATH, Pra-dip & $\begin{array}{l}\text { Doença de coronavírus } 2019 \\
\text { (COVID-19) pandemia e } \\
\text { gravidez }\end{array}$ & $\begin{array}{l}\text { Resumir as características clínicas de mu- } \\
\text { lheres gravidas com COVID-19 e apresen- } \\
\text { tar uma estrutura pragmática e integrada } \\
\text { que aborda as complexidades obstétricas } \\
\text { do manejo desta doença na gravidez. }\end{array}$ \\
\hline $4^{\circ}$ & Abril/2020 & DUARTE, Geraldo & $\begin{array}{l}\text { COVID-19 em obstetrícia. } 0 \\
\text { que é preciso saber? }\end{array}$ & $\begin{array}{l}\text { Evidenciar as informações relacionadas aos } \\
\text { aspectos gestacionais e perinatais median- } \\
\text { te ao novo coronavirus. }\end{array}$ \\
\hline $5^{\circ}$ & Março /2020 & $\begin{array}{l}\text { Sociedade brasileira de } \\
\text { medicina de família e co- } \\
\text { munidade }\end{array}$ & $\begin{array}{l}\text { Gravidez e Corona-virus: con- } \\
\text { fira as evidências }\end{array}$ & $\begin{array}{l}\text { Apresentar estratégias de segurança no } \\
\text { manejo de gestantes e puérperas no con- } \\
\text { texto da pandemia de coronavirus. }\end{array}$ \\
\hline $6^{\circ}$ & Abril/2020 & Ministério da saúde & $\begin{array}{l}\text { Nota técnica 10: Atenção á } \\
\text { saúde do recém-nascido no } \\
\text { contexto da infecção pelo } \\
\text { novo coronavirus (SARS- } \\
\text {-Cov-2) }\end{array}$ & $\begin{array}{l}\text { Orientar as medidas para enfrentamento } \\
\text { da emergência de saúde pública de impor- } \\
\text { tância internacio-nal decorrente do corona- } \\
\text { virus responsável pelo surto de } 2019\end{array}$ \\
\hline
\end{tabular}




\section{artigo}

Ramiro, N.C.M.P.; Pereira, M.S.; Souza, R.S.; Aver, L.A.;

Repercussões fetais e possiveis complicações da COVID-19 durante a gestação

\begin{tabular}{|c|l|l|l|l|}
\hline $7^{\circ}$ & Março/2020 & $\begin{array}{l}\text { Sociedade Brasileira de } \\
\text { Pediatria de São Paulo }\end{array}$ & $\begin{array}{l}\text { Coronavirus e recém-nascido: } \\
\text { oque se sabe até o momento }\end{array}$ & $\begin{array}{l}\text { Atualizar a revisão sobre coronavírus e re- } \\
\text { cém-nascido }\end{array}$ \\
\hline $8^{\circ}$ & Abril/2020 & $\begin{array}{l}\text { RONDELLI, Giuliana Paola } \\
\text { Hoeppner et al }\end{array}$ & $\begin{array}{l}\text { Atualização às gestantes e } \\
\text { recém-nascidos no contexto } \\
\text { da infecção COVID-19: uma } \\
\text { revisão sistemática }\end{array}$ & $\begin{array}{l}\text { Explorar e sintetizar as evidências dispo- } \\
\text { niveis na literatura cientifica voltadas para } \\
\text { atenção e o manejo das gestantes e re- } \\
\text { cém-nascidos suspeitos ou infectados pelo } \\
\text { virus SARS-CoV-2. }\end{array}$ \\
\hline $9^{\circ}$ & Março/2020 & RAMALHO, Carla & $\begin{array}{l}\text { COVID-19 na gravidez, o que } \\
\text { sabemos? }\end{array}$ & $\begin{array}{l}\text { Sintetizar as informações sobre a ocorrên- } \\
\text { cia de complicações no âmbito da pande- } \\
\text { mia do novo coronavirus na gestação. }\end{array}$ \\
\hline $10^{\circ}$ & Abril/2020 & $\begin{array}{l}\text { SAIDAH, Mohamed Kas- } \\
\text { sen }\end{array}$ & $\begin{array}{l}\text { COVID-19: Manejo em ges- } \\
\text { tantes }\end{array}$ & $\begin{array}{l}\text { Orientar os profissionais da saúde no aten- } \\
\text { dimento de gestantes que apresentarem } \\
\text { resultado positivo para o COVID-19. }\end{array}$ \\
\hline $11^{\circ}$ & Abril/2020 & Ministério da saúde & $\begin{array}{l}\text { Nota técnica 7: Atenção as } \\
\text { gestantes no contexto da } \\
\text { infecção COVID-19 causado } \\
\text { pelo novo coronavirus (SAR- } \\
\text { S-CoV-2) }\end{array}$ & $\begin{array}{l}\text { Orientar as medidas que devem ser adota- } \\
\text { das na atenção á saúde das gestantes no } \\
\text { contexto da pandemia do novo coronavirus } \\
\text { (SARS-CoV-2) }\end{array}$ \\
\hline
\end{tabular}

\section{Figura 3. Quadro sinóptico dos artigos selecionados contendo título e resultados. São Paulo, SP, Brasil, 2020}

\begin{tabular}{|c|c|c|}
\hline NUMERAÇÃO & TÍTULO & RESULTADOS \\
\hline $1^{\circ}$ & $\begin{array}{l}\text { Coronavírus na gravidez: con- } \\
\text { siderações e recomendações - } \\
\text { SOGI-MIG }\end{array}$ & $\begin{array}{l}\text { De acordo com os estudos encontrados, as gestantes infectadas por coronavírus } \\
\text { tendem a apresentar um quadro clínico semelhante ao de adultos não grávidos, } \\
\text { incluindo sintomas como febre, tosse e linfopenia. }\end{array}$ \\
\hline $2^{\circ}$ & $\begin{array}{l}\text { Gestantes no contexto da pan- } \\
\text { demia da COVID-19: reflexões e } \\
\text { desafios }\end{array}$ & $\begin{array}{l}\text { Há sintomas que podem aparecer com menor intensidade nas gestantes como, } \\
\text { por exemplo, fadiga, dispneia, diarreia, congestão nasal e até complicações mais } \\
\text { graves como Síndrome Respiratória Aguda Grave (SRAG). }\end{array}$ \\
\hline $3^{\circ}$ & $\begin{array}{l}\text { Doença de coronavírus } 2019 \\
\text { (COVID-19) pandemia e gravidez }\end{array}$ & $\begin{array}{l}\text { Ainda não há estudos conclusivos correlacionando o risco de malformações con- } \\
\text { gênitas ao vírus. }\end{array}$ \\
\hline $4^{\circ}$ & $\begin{array}{l}\text { COVID-19 em obstetrícia. O que é } \\
\text { preciso saber? }\end{array}$ & $\begin{array}{l}\text { Em estudos que evidenciam os aspectos obstétricos e perinatais, realizados ao } \\
\text { redor do mundo, observou-se elevado índice de partos pré-termos e significativa } \\
\text { taxa de prematuridade associada à mortalidade fetal. Além disso, evidenciou-se } \\
\text { a ausência de mortalidade materna, na qual a maioria das gestantes apresentou } \\
\text { a doença em seu quadro leve. }\end{array}$ \\
\hline $5^{\circ}$ & $\begin{array}{l}\text { Gravidez e Coronavírus: confira as } \\
\text { evidências }\end{array}$ & $\begin{array}{l}\text { Através de análises de gestantes positivas para Covid-19, pode-se identificar } \\
\text { como principal evento adverso para o bebê, o nascimento prematuro. }\end{array}$ \\
\hline $6^{\circ}$ & $\begin{array}{l}\text { Nota técnica 10: Atenção á saúde } \\
\text { do recém-nascido no contexto da } \\
\text { infecção pelo novo coronavirus } \\
\text { (SARS-Cov-2) }\end{array}$ & $\begin{array}{l}\text { Atualmente sabe-se que não ocorre transmissão vertical, ou seja, transmissão } \\
\text { via placentária para o feto. Além disso, estudo realizados com crianças chinesas } \\
\text { mostrou que crianças menores de } 1 \text { ano têm maiores chances de desenvolverem } \\
\text { complicações mais severas. }\end{array}$ \\
\hline $7^{\circ}$ & $\begin{array}{l}\text { Coronavírus e recém-nascido: } 0 \\
\text { que se sabe ate o momento }\end{array}$ & $\begin{array}{l}\text { Nos casos em que mães sadias não apresentam patologia crônica, os recém-nas- } \\
\text { cidos de mães com Covid-19 apresentam condições de saúde leve a moderada, } \\
\text { sendo mínimos os casos críticos, embora ainda possuam imaturidade no sistema } \\
\text { imunológico. }\end{array}$ \\
\hline $8^{\circ}$ & $\begin{array}{l}\text { Atualização às gestantes e } \\
\text { recém-nascidos no contexto da } \\
\text { infecção COVID-19: uma revisão } \\
\text { sistemática }\end{array}$ & $\begin{array}{l}\text { A história pregressa materna influencia diretamente no prognóstico da gestante, } \\
\text { dado que doenças crônicas como Diabetes Mellitus, Hipertensão arterial, asma e } \\
\text { doença pulmonar obstrutiva crônica (DPOC) apresentam taxas elevadas de com- } \\
\text { plicações, como pré-eclâmpsia e insuficiência hepática em alguns casos. }\end{array}$ \\
\hline
\end{tabular}


Durante essa crise da COVID-19, não é indicado o acompanhante no acompanhamento da gravidez, com exceção do trabalho de parto, para que possa minimizar o fluxo hospitalar, diminuindo o risco de exposição ao vírus ${ }^{(5)}$.

Ao atender um caso suspeito ou confirmado da COVID-19, deve ser oferecida máscara cirúrgica à paciente, sendo que a mesma para o paciente parece ser suficiente visto que a disseminação viral se faz por gotículas. Para a equipe profissional, está indicado uso de equipamentos de proteção individual (EPI), incluindo: óculos, máscara N95, protetor facial, avental e gorro. Sendo que ao longo de todo o atendimento deve-se seguir a regra de ouro na contenção da pandemia do SARS-CoV-2, a melhor estratégia continua sendo a higienização das mãos (água e sabão, álcool gel) e degermação de superfícies e materiais contaminados com álcool, cloro, alguns fenóis, iodóforos e quaternário de amônio ${ }^{(1)}$.

É importante salientar que a taxa de mortalidade de grávidas acometidas pela COVID-19 não se mostra superior à taxa de mortalidade de gestantes não infectadas, e que apresentam as mesmas características gestacionais. Desta forma, as evidências mostram que a probabilidade de complicações em gestantes é a mesma que a da população geral. Todavia, devemos estar atentos a grávidas que possuem Hipertensão Arterial Sistêmica (HAS), Diabetes Mellitus (DM) e patologias pulmonares crônicas (asma, DPOC, tabagismo, entre outras), pois estas possuem taxas de complicações elevadas ${ }^{(6)}$.

A sintomatologia apresentada pela mulher grávida é bastante comum àqueles sintomas apresentados pela população geral, sendo: febre, mialgia, dor de garganta e tosse. Sendo que a alteração laboratorial mais frequente foi a alinfocitopenia ${ }^{(6)}$.

Como qualquer gestação, a gestante precisa realizar o pré-natal,

\section{Durante essa}

crise da COVID-19,

não é indicado

o acompanhante

no acompanhamento

da gravidez,

com exceção do

trabalho de parto,

para que possa

minimizar

o fluxo

hospitalar,

diminuindo o

risco de exposição

ao vírus ${ }^{(5)}$. porém os procedimentos realizados durante o mesmo serão alterados de acordo com o nível de acometimento do coronavírus na gestante, todas as gestantes com sinais de COVID-19 leve (confirmadas ou não): deve-se investigar a presença de gravidade (ex: dispneia, dor torácica, taquipneia, desidratação, hemoptise, dentre outros) na anamnese e durante o exame físico. $\mathrm{Na}$ ausência de sinais de gravidade e comorbidade que contraindiquem o acompanhamento ambulatorial, a paciente deverá ser encaminhada para o ambiente domiciliar, para isolamento social e cuidados de suporte, como: uso de analgésicos comuns, hidratação oral frequente e repouso. É essencial que a gestante esteja bem orientada sobre os sinais de agravamento para que possa procurar a maternidade de referência sem atrasos ${ }^{(7)}$.

Enquanto em casos mais graves de COVID-19 (confirmados ou não): avaliar as gestantes cuidadosamente tentando avaliar o impacto da doença respiratória. A gestante deverá ser encaminhada para a maternidade de referência para avaliar necessidade de propedêutica complementar e internação por equipe multidisciplinar. Esse grupo específico de gestantes, possivelmente, necessitará da realização de exames radiológicos, tais como radiografia de tórax e TC de tórax para definição do contexto clínico. Caso sejam considerados necessários, deverão ser realizados sem atrasos ${ }^{(8)}$.

As gestantes contaminadas com o SARS-CoV-2, além da sintomatologia, ainda podem apresentar complicações que podem colocar em risco a saúde materna, essas complicações normalmente são insuficiência respiratória progressiva e sepse grave. Essas complicações ocorrem dada a predisposição a infecções bacterianas sobrepostas devido à lesão mucosa direta, desregulação das respostas imunes e alterações no microbioma respiratório após pneumonia viral. Sendo que a deterioração materna pós-natal 


\section{artigo}

Ramiro, N.C.M.P.; Pereira, M.S.; Souza, R.S.; Aver, L.A.;

Repercussões fetais e possiveis complicações da COVID-19 durante a gestação

ainda pode ocorrer, necessitando de monitoramento contínuo ${ }^{(9)}$.

Com relação ao feto, não está claro o impacto da COVID-19 no ambiente intrauterino, da mesma forma que não se sabe se ocorre a transmissão vertical durante uma infecção materna, porém, baseando-se nos quadros de pneumonias de outras etiologias na gestação, existe o risco da COVID-19 determinar repercussões fetais ${ }^{(8)}$.

As possíveis repercussões fetais da COVID-19 incluem aborto espontâneo, restrição de crescimento intrauterino (RCIU) e parto prematuro. A febre, com temperatura mediana de 38,1 a 39,0 o C na mãe, é o sintoma predominante da COVID-19, sendo importante salientar que estudos de coorte em pacientes com outras infecções não demonstraram riscos aumentados de anomalias congênitas por pirexia materna no primeiro trimestre, embora os distúrbios de desatenção na infância sejam mais comuns, possivel- mente relacionados a lesões hipertérmicas nos neurônios fetais ${ }^{(10)}$.

É importante lembrar que as gestantes acima de 28 semanas devem realizar o isolamento social e medidas de prevenção da patologia causado pelo SARS-CoV-2, por conta do risco de prematuridade e necessitando que o recém-nascido receba cuidados intensivos neonatais.

O parto da gestante que está contaminada com a COVID-19 é indicado que se realize de forma vaginal, sendo que o parto cesariana só será realizado em casos de insuficiência respiratória, ambos os partos devem ser realizados em sala isolada; se sabe até o momento que o parto via vaginal continua sendo a forma mais adequada para a resolução da gravidez para gestantes portadoras da COVID-19. Para casos com insuficiência respiratória, as orientações sustentam a indicação de cesárea. Nesses casos, será necessário discutir o caso com o anestesista e o neonatologista, principalmente para fetos pré-termo ${ }^{(1,11)}$.

\section{CONCLUSÃO}

Por se tratar de uma patologia nova, a quantidade de dados disponíveis que abordam sua repercussão na gestação é escassa, por tanto, por se tratar de uma situação crítica, há a necessidade de buscar alternativas para realizar no manejo dessas grávidas que têm suspeita ou que já estão confirmadas para a COVID-19. Os estudos existentes sobre COVID-19 são baseados em evidências e experiências que foram adquiridas em outros países que foram acometidos por essa doença previamente, desta forma, conseguem nortear a melhor conduta em pacientes gestantes e desse feto. Nota-se que por ser uma patologia altamente contagiosa, os cuidados com essa mãe e esse feto devem ser mais cautelosos para evitar complicações, que por se tratar de uma gestante estão mais suscetíveis.

\section{REFERÊNCIAS}

1. Duarte G. COVID-19 em obstetrícia. O que é preciso saber? São Paulo: Frebasgo; 2020.

2. Ministério da Saúde (BR). Nota Técnica n. 10/2020 - COCAM/CGCIVI/DAPES/SAPS/MS [Internet]. 2020 [acesso em 16 mai 2020]. Disponível em: http://189.28.128.100/dab/ docs/portaldab/documentos/notatecnica102020COCAMCGCIVIDAPESSAPSMS_003.pdf.

3. Saidah MK. COVID-19: Manejo de Gestantes. Goiana: Sociedade Goiana de Ginecologia e Obstetrícia; 2020.

4. Rondelli GPH, et al. Assistência às gestantes e recém-nascidos no contexto da infecção COVID-19: uma revisão sistemática. Revista Desafios [Internet]. 2020 [acesso em 18 mai 2020]; 7(Supl. COVID-19). Disponível em: https:// sistemas.uft.edu.br/periodicos/index.php/desafios/article/view/8943/16730.

5. Estrela FM. Gestantes no contexto da pandemia da Covid-19: reflexões e desafios. Rio de Janeiro: Physis: Revista de Saúde Coletiva; 2020.

6. Dashraath P. Doença de coronavírus 2019 (COVID-19) pandemia e gravidez. Singapura: Elsevier; 2020.

7. Sociedade Brasileira de Medicina de Família e Comuni- dade (BR). Gravidez e coronavírus: confira as evidências [Internet]. 2020 [acesso em 15 mai 2020]. Disponível em: https://www.sbmfc.org.br/noticias/gravidez-e-coronavirus-confira-as-evidencias/.

8. Osanan GC. Coronavírus na gravidez: considerações e recomendações SOGIMIG. Belo Horizonte: SOGIMIG; 2020.

9. Sociedade de Pediatria de São Paulo. Coronavírus e recém-nascido: 0 que se sabe até o momento? [Internet]. 2020 [acesso em 16 mai 2020]. Disponível em: https:// www.spsp.org.br/2020/03/30/coronavirus-e-recem-nascido-o-que-se-sabe-ate-o-momento-30-03-2020/.

10. Ramalho C. COVID-19 na gravidez, o que sabemos? Acta Obstet Ginecol Port [Internet]. 2020 mar [acesso em 18 mai 2020]; 14(1). Disponivel em: http:// www.scielo.mec.pt/scielo.php?script=sci_arttext\&pi$d=S 1646-58302020000100001$.

11. Ministério da Saúde (BR). Nota Técnica n. ${ }^{\circ} 7 / 2020$ COSMU/CGCIVI/DAPES/SAPS/MS [Internet]. 2020 [acesso em 18 mai 2020]. Disponível em https://portaldeboaspraticas.iff.fiocruz.br/wp-content/uploads/2020/04/notatecnicagestantes 72020 COCAMCGCIVIDAPESSAPSMS03abr2020COVID-19.pdf 